\title{
Patrick Wald Lasowski, Le Traité des mouches secrètes
}

\section{Valentina Ponzetto}

\section{(2) OpenEdition}

\section{Journals}

\section{Edizione digitale}

URL: http://journals.openedition.org/studifrancesi/33283

DOI: 10.4000/studifrancesi.33283

ISSN: 2427-5856

\section{Editore}

Rosenberg \& Sellier

\section{Edizione cartacea}

Data di pubblicazione: 1 décembre 2005

Paginazione: 649

ISSN: 0039-2944

\section{Notizia bibliografica digitale}

Valentina Ponzetto, «Patrick Wald Lasowski, Le Traité des mouches secrètes», Studi Francesi [Online], 147 (XLX | III) | 2005, online dal 30 novembre 2015, consultato il 18 avril 2021. URL: http://

journals.openedition.org/studifrancesi/33283 ; DOI: https://doi.org/10.4000/studifrancesi.33283

Questo documento è stato generato automaticamente il 18 avril 2021. 


\title{
Patrick Wald Lasowski, Le Traité des mouches secrètes
}

\author{
Valentina Ponzetto
}

\section{NOTIZIA}

PATRICK WALD LASOWSKI, Le Traité des mouches secrètes, Paris, Gallimard («Le promeneur»), 2003, pp. 118.

1 Un'ineffabile leggerezza, e un certo divertito tocco di mistero, presiedono fin dal titolo al Traité des mouches secrètes. Patrick Wald Lasowski gioca infatti, maliziosamente, con la polisemia rivestita nel francese settecentesco dal termine «mouches». Insetti, certo, che servono di metafora ad un secolo svolazzante e inquieto, sempre sospeso fra sucrerie e pourriture, o che, nella varietà cantharides, arricchiscono di droghe afrodisiache e letali i banchetti dei libertini. Ma anche, e soprattutto, mouchards, spie della polizia, informatori, gazzettieri più o meno autorizzati, e infine mouches galantes, nei finti, di taffetas, da posarsi con arte sottile, secondo un codice tanto raffinato quanto malizioso, sul viso, e non solo.

2 Al centro di questo libro, e variamente legato alle mouches in tutte le diverse accezioni del termine, è il cavaliere de Mouhy, curioso e poco noto personaggio, che l'autore ci accompagna a conoscere attraverso una gustosa serie di aneddoti e testimonianze d'epoca, disegnando al tempo stesso uno spaccato formicolante di vita e di avventure del sottobosco culturale e galante della Parigi settecentesca.

3 Le chevalier de Mouhy è infatti, prima di tutto, un informatore. Dal grande ed anonimo pubblico ai potenti, dai letterati alla polizia, a tutti egli offre le sue notizie e i suoi servigi. Patrick Wald-Lasowski lo segue così nelle sue complesse vicissitudini di attivissimo correspondant littéraire per Voltaire, prima di diventare suo oppositore e denigratore, di corrispondente del cardinal de Tencin, di Stanislas Laszczynski e del maresciallo di Belle-Isle, di informatore segreto della polizia, e di infaticabile gazzettiere, autore dapprima di fogli volanti manoscritti contenenti novità teatrali, 
galanti, militari e altre rumeurs cittadine, poi di un periodico di notizie di Parigi, pubblicato in Olanda e intitolato significativamente Le Papillon, ou Lettres parisiennes, ouvrage qui contiendra tout ce qui se passe d'intéressant, de plus agréable et de plus nouveau dans tous les genres.

4 La stessa, irrefrenabile smania di venire a conoscenza di tutto, e tutto spifferare, anima anche Brigand, il protagonista del più noto (o del meno dimenticato) romanzo di Mouhy: La Mouche, storia, per l'appunto, di un delatore. Perché Mouhy è anche un romanziere, anzi, «le romancier le plus prolifique du XVIII ${ }^{\mathrm{e}}$ siècle», come scrive l'autore, che traccia di lui il vivido ritratto di un artigiano della letteratura, torrenziale, trasandato, pieno di immaginazione, senza stile e senza scrupoli, pronto ad impadronirsi dei successi del giorno per fame all'istante la parodia, o il calco. Fréron, Grimm, Voisenon, ed altri ancora dedicano agli scritti del cavaliere pagine impietose, qui trascritte per diletto del lettore.

$5 \quad$ Fra le tante opere attribuite a Mouhy ci sarebbe anche un Traité des mouches secrètes, che offre a Patrick Wald Lasowski, oltre al titolo del suo saggio, l'occasione per una digressione sui capricci delle toilettes tanto maschili quanto femminili del secolo di Luigi $\mathrm{XV}$, dove le mouches, ovviamente, hanno un posto d'onore. Ciascuna porta un nome diverso, secondo la posizione. A quelle che si posano sul viso, la passionnée, la baiseuse, l'enjouée, l'effrontée, l'immaginazione di Mouhy ne aggiunge altre, più segrete, dalla Brèche, che si posa sul collo del piede, fino al Diable au corps, da mettersi niente meno che sul sesso. «Le corps se laisse redécouvrir. Jusqu'aux terres dangereuses. De la première Brèche au Diable au corps, l'itinéraire est multiple. Il est recommandé d'être vagabond», scrive Wald Lasowski nella sua prosa leggera, insinuante, squisitamente settecentesca. 